work, with a mass of useful information compressed into a small space. Dr. J. Gross deals with the thyroid hormones and includes an account of the recent discoveries which he and Mrs. R. Pitt-Rivers have made on the various iodine compounds in the thyroid gland and in the blood. Much of this important work would have been impossible without the use of paper chromatography in combination with tracer technique using radioactive iodine, which permitted analyses to be made on an ultra-micro scale. This article, and the one by Drs. C. E. Dent and J. M. Walshe on amino-acid metabolism, are of direct medical appeal.

Some of the articles contain a good deal of hitherto unpublished work, and each includes a bibliography which greatly adds to the value of the publication. Incidentally, references to Nature, which is being regularly used as a forum for the recording and exchange of new chromatographic procedures, appear frequently in these bibliographies. It seems a pity that all the illustrations in a volume entitled "Chromatography" should be produced in black-andwhite. Some private journals, notably Endeavour, have shown what æesthetically pleasing results can be achieved by the use of colour in illustrating chromatographic techniques, even if, from a purely scientific point of view, the gain does not justify the large extra cost. No worker who is interested in chromatography, whether beginner or expert, can fail to benefit from reading this admirable publication. It is likely to be used on the laboratory bench as well as in the library, and it deserves to be protected from accidental 'paper chromatography' by being given a permanent, binding.

D. C. HARRISON

\section{THE EXPANDING UNIVERSE}

A SLIGHTLY modified version of a talk given by G. J. Whitrow in February 1953 in the B.B.C. Third Programme has now been published as a paper under the title of "The Orthodox Theory of the Expanding Universe" in the October issue of Occasional Notes of the Royal Astronomical Society $(17,3 ;$ 1954). A fairly large portion of the talk is concerned with a work by Paul Couderc, a French astronomer, which appeared in a French edition in 1950 and was translated into English by J. B. Sidgwick under the title "The Expansion of the Universe" (1952). The first part of the talk gives a very useful résumé of the developments in our knowledge of the universe during the past thirty years, in which period it was accepted that the universe extends far beyond the limits of our galaxy, and also that the red shift strongly suggested the recession of the extra-galactic nebula, all of which were moving away from one another. The talk then considers other interpretations that have been given to the displacement towards the red end of the spectrum, dealing in particular with various matters connected with Couderc's book.

This book is recognized as a very useful contribution to cosmology in so far as it provides us with a simplified account of the mathematical theory of the expanding universe ; but in recent years some British cosmologists have advocated a new theory based on the hypothesis of the continuous creation of matter. Differences of view arise regarding the form in which this new matter emerges. C. Pascual Jordan advocates the formation of super-giant stars; but other cosmologists who challenge this view have put forward the conception of new matter appearing in the form of hydrogen molecules or even neutrons, and the density of the universe remains constant, the decrease in density which would result from the recession of the galaxies being exactly balanced by the continuous creation of matter. As might be expected, these theories have been subjected to severe criticisms; nevertheless, they are able to claim one strong argument in their favour-that they allow more time for stellar evolution than the older orthodox view which led to a conception of the earth being older than the galaxies. This argument is no longer valid since Baade's announcement about the wrong 'calibration' of the distances of the Cepheid variables (the investigations of Thackeray and Wesselink on the distance of the Magellanic Clouds have corroborated Baade's conclusions); now it seems that it must have been about four thousand million years ago since the universe started expanding, and in addition, the distances of the extra-galactic nebulæ must now be taken as twice those previously estimated.

Whitrow concludes with an expression of disagreement with Couderc's acceptance of the two fundamental hypotheses at the basis of the 'orthodox' theory of the expanding universe; these are that the red shifts are due to the Doppler effect associated with recessional motion, and also that the laws of Einstein's general theory of relativity, either with or without the idea of cosmical repulsion, govern the structure of the universe as a whole. He thinks that neither of these is on such firm foundations as Coudere believes; but in spite of this disagreement he speaks highly of the latter's book which, on p. 213, seems to express a little doubt on the inadequacy of some of his own arguments. "Everything possible has been extracted from existing observations; until the appearance of new data we would be wise to give our imaginations a rest." To this remark Whitrow makes the very relevant reply : ". . . if such advice had been accepted by Copernicus he would never have ventured beyond the Ptolemaic theory".

\section{RECENT MOLLUSCA OF CANADA}

$\mathrm{T}$ HE great extent of Canada has resulted, and will probably long result, in its molluscan fauna being studied in four separate areas: the Eastern Provinces, British Columbia, the Arctic region based on Hudson Bay, and the Prairie Provinces. In the first three, marine, freshwater and land forms are involved, but in the fourth only freshwater and land. Partly for this reason and also because many of the species were first described from other countries, the literature involved is extensive and scattered.

A very useful service in rendering this literature and its results available for the whole of Canada has been performed by the publication of Bulletin No. 129 of the National Museum of Canada, entitled "Cata. logue of the Recent Mollusca of Canada", by Dr. Aurèle La Rocque (Biological Series No. 44. Pp. ix +406. Ottawa: Queon's Printer, 1953; 2.50 dollars). It fills a very obvious gap, for it provides a list of the accepted species and forms that have so far been recorded, numbering about 2,250. The author has wisely included forms that have actually 